\title{
Selective screening for familial hypercholesterolemia in Austrian children - first year results
}

\author{
Alexandra Kreissl', Nina Walleczek', Pinky Rose Espina', Ulrike Hallwirth² and Susanne Greber-Platzer ${ }^{1 *}$
}

\begin{abstract}
Background: Familial hypercholesterolemia $(\mathrm{FH})$, the most frequent monogenetic hereditary disorder, is underdiagnosed and undertreated. Early identification of FH is essential because of the increased risk for premature cardiovascular diseases and childhood might be the optimal period for cholesterol screening. Aim of this selective screening was to detect familial hypercholesterolemia, the most frequent monogenetic hereditary disorder in children to guarantee early detection and treatment. The Austrian strategy for primary schools, to perform a pre-school examination by school physicians, allows to reach all children aged 5-7 years.

Methods: The screening was conducted within the school enrolment examinations in all 215 public primary schools in Vienna between January to May 2017. Positive cholesterol screening was defined by non-HDL-C $>160 \mathrm{mg} / \mathrm{dL}$ and/or LDL-C $>130 \mathrm{mg} / \mathrm{dL}$.

Results: In total, 18,152 children had their school enrolment examination. From 133 tested pre-school children, nine individuals were positive-screened with a mean LDL-C of $161 \pm 26 \mathrm{mg} / \mathrm{dL}$, non-HDL-C of $181 \pm 24 \mathrm{mg} / \mathrm{dL}$ and total cholesterol (TC) of $239 \pm 23 \mathrm{mg} / \mathrm{dL}$. From 85 siblings, four individuals were positively screened with a mean LDL-C of $150 \pm 7 \mathrm{mg} / \mathrm{dL}$, non-HDL-C of $184 \pm 8 \mathrm{mg} / \mathrm{dL}$ and TC of $231 \pm 10 \mathrm{mg} / \mathrm{dL}$. Patients did not have any xanthomas, xanthelasms, arcus lipoides, or any cardiovascular comorbidities.

Conclusions: Screening at early childhood by school physicians seems to be a successful strategy and possible. With this Austrian selective screening method, FH Kids Austria, we could find nine patients with positive raised level LDLcholesterol and/or non-HDL cholesterol out of 133 blood tests. Prevention of cardiovascular diseases is essential and it is our duty to increase the awareness of this disease. Limitations of the FH Kids project were reduced participation of school physicians and refusal of the parents.
\end{abstract}

Keywords: Familial hypercholesterolemia, Selective screening, Cholesterol, LDL cholesterol, Children

\section{Background}

Familial hypercholesterolemia (FH) is the most frequent monogenetic hereditary disorder and a common cause of premature cardiovascular diseases (PCVD) [1]. The relationship between morbidity and mortality to early treatment seems to be essential $[1,2]$. Therefore, early detection and strict therapy are necessary to prevent PCVD. Heterozygous familial hypercholesterolemia $(\mathrm{heFH})$ is an autosomal dominant disease. $\mathrm{FH}$ is

\footnotetext{
* Correspondence: susanne.greber-platzer@meduniwien.ac.at

${ }^{1}$ Division of Pediatric Pulmonology, Allergology and Endocrinology,

Department of Pediatrics and Adolescent Medicine, Medical University of

Vienna, Waehringer Guertel 18-20, 1090 Vienna, Austria

Full list of author information is available at the end of the article
}

characterized by markedly elevated plasma concentrations of low density lipoprotein cholesterol (LDL-C), which are already present at birth [3]. FH is caused by genetic mutations of the LDL-receptor (LDL-R), Apolipoprotein B (ApoB), proprotein convertase subtilisin/kexin type 9 (PCSK9) or low-density lipoprotein receptor adaptor protein 1 (LDLR-AP1) [4]. The prevalence of heterozygous familial hypercholesterolemia is between 1 per 250 in the European population [5-7]. The prevalence of homozygous familial hypercholesterolemia (hoFH) is between 1 per 160,000 to 300,000 [5-8].

Familial hypercholesterolemia is underdiagnosed and undertreated according to the following facts: i) the

(c) The Author(s). 2019 Open Access This article is distributed under the terms of the Creative Commons Attribution 4.0 International License (http://creativecommons.org/licenses/by/4.0/), which permits unrestricted use, distribution, and reproduction in any medium, provided you give appropriate credit to the original author(s) and the source, provide a link to the Creative Commons license, and indicate if changes were made. The Creative Commons Public Domain Dedication waiver (http://creativecommons.org/publicdomain/zero/1.0/) applies to the data made available in this article, unless otherwise stated. 
disease and its high frequency is still largely unknown among the general population, ii) missing symptoms in patients, especially in children and adolescents, and iii) screening strategies are globally inconsistent or even not available. Three types of screening can be distinguished: the selective screening, cascade screening and the universal screening. Selective screening for $\mathrm{FH}$ is based on the measurement of cholesterol levels in children, with a positive family history for hypercholesterolemia or premature cardiovascular disease in first- or second-degree relatives [9-11]. Cascade screening can describe a direct cascade screening or a reverse cascade screening. Direct cascade screening is based on the known genetic defect for a disease of an individual, indicating genetic testing in all first-degree relatives. This type of screening is the most cost-effective strategy for FH [12, 13]. Reverse cascade screening is based on the fact that a child is the index patient, followed by testing in the parents and other relatives [14]. In universal screening a nationwide measurement for example of cholesterol is performed in a certain age group of childhood $[15,16]$.

The aim of the study, FH Kids Austria, was to detect $\mathrm{FH}$ in young aged children and to guarantee early detection and treatment. The Austrian strategy for primary schools, to perform a pre-school examination by school physicians, allows to reach all children aged 5 to 7 years and their parents. Therefore, a selective screening strategy for familial hypercholesterolemia was considered as most suitable and as considered feasible by school physicians.

\section{Methods}

\section{Study design}

This prevention-study was implemented to identify children with familial hypercholesterolemia with a selective screening in primary school children aged between 5 to 7 years. The screening was conducted within the school enrolment examinations in all 215 public primary schools in Vienna between January to May 2017. The screening was based on three questionnaires, the school physician questionnaire about the child and a questionnaire for each parent available in German, English, Turkish and Bosnian-Croatian-Serbian. Each questionnaire included three short questions and thus many negative families were able to be eliminated for screening.

Questionnaire:

1) Do you (biological mother or father) or close relatives (siblings, grandparents, aunts, uncles) have elevated blood lipids (= total cholesterol, triglycerides, LDLcholesterol) or does someone take cholesterol-lowering medication (statins)?

$\mathrm{O}$ Yes O No if yes: please specify on you / your relatives:
2) Do you (biological mother or father) have fatty skin lumps (=xanthomas) in particular on the areas of the Achilles tendon/ hands/knees or eyes (=xanthelasma)?

O Yes O No.

3) Did you (biological mother or father) or close relatives (siblings, grandparents, aunts, uncles) suffered a heart attack or stroke before the age of 55 ?

Parents were contacted if one of the questions were positively answered, not-answered or unknown answers (e.g. foster or adopted child) were provided.

\section{Cholesterol level determination}

Cholesterol screening test was performed with the Alere AfinionTM AS 100 Analyzer (Alere GmbH, Linz, Austria) at the Department of Pediatrics and Adolescent Medicine at the Medical University of Vienna from January to September 2017. The cholesterol screening test was taken from a capillary blood sampling from a puncture on the finger. The measured blood parameters included total cholesterol (TC), high-density lipoprotein cholesterol (HDL-C), and triglycerides (TG). Lowdensity lipoprotein cholesterol (LDL-C), non-HDL cholesterol (non-HDL-C), and cholesterol/high-density lipoprotein cholesterol ratio (C/HDL-C ratio) were calculated by the device. The cut-off level for a positive cholesterol blood screening was defined either as strong positive by non-HDL-C $>190 \mathrm{mg} / \mathrm{dL}$ and/or LDL-C > $160 \mathrm{mg} / \mathrm{dL}$ or as borderline by non-HDL-C $>160 \mathrm{mg} / \mathrm{dL}$ and/or LDL-C $>130 \mathrm{mg} / \mathrm{dL}$. The pre-school children as well as their siblings were tested. Positive screened children as well as individuals were invited to follow the standardized familial hypercholesterolemia program at the outpatient clinic of obesity, lipometabolic disorder and nutritional medicine at the Department of Pediatrics and Adolescent Medicine. The study was approved by the local Ethics-Committee at the Medical University Vienna (MUV, EC Nr: 2019/2015). All parents were informed and provided their written informed consent.

\section{Statistical methods}

Metric variables are shown as median, range and mean with SD and dichotomous variables were described by absolute and relative frequencies. All statistical analyses were performed using the software Statistical Package for Social Science for Windows version 24 (SPSS Inc., Chicago, USA).

\section{Results}

\section{Study population}

A total of 18.152 children had their school enrolment examination, 6.325 answered the questionnaires and 229 provided positive questionnaires, defined as questions which were positively answered, not-answered 
or unknown answers. Finally, 133 pre-school children came to the clinic for the lipid screening test (Fig. 1). Vienna consists of 23 districts and the majority of the tested pre-school children came from the second district (Leopoldstadt) (15.4\%), third district (Landstraße) (15.4\%) and the 12th district (Meidling) (10\%). Biological mothers were from 20 different countries of birth and biological fathers from 23 different countries of birth. The majority came from Austria, with the same percentage of $41.4 \%$ in both parents, followed by Turkey (mothers: 9.8\%, fathers: 11.3\%). The mothers age was 36 years (=median, range: $22-$ 50 years) and fathers were 39 years (=median, range: $23-53$ years) old. An amount of $22 \%$ of mothers and $35 \%$ of fathers indicated in the questionnaire to suffer from hypercholesterolemia. Xanthomas and xanthelasma were present in $2.3 \%$ mothers and in $3.8 \%$ fathers respectively. More fathers (9.8\%) than mothers (3.8\%) suffered from coronary heart disease (CHD). More first- and second-grade relatives of mothers $(60.2 \%)$ than of fathers (40.6\%) suffered from hypercholesterolemia. A premature coronary heart disease has been determined in $37.6 \%$ of maternal close relatives and in $17.3 \%$ of paternal close relatives. The pre-school children had up to three siblings. The flow diagram visualizes the implementation of the screening (Fig. 1).

\section{Patient characteristics}

The demographic data are presented in Table 1. In $11 \%$ of the pre-school children, the following diseases have been noticed: obesity $(n=5)$, allergy $(n=2)$, neurodermatitis $(n=1)$, obstipation $(n=2)$, iron deficiency $(n=1)$, kidney disease $(n=1)$, epilepsia $(n=1)$ and myositis $(n=1)$. Clinical symptoms of $\mathrm{FH}$ were not determined in these children.

\section{Cholesterol screening test}

Out of the 133 pre-school children, nine individuals were positively screened with a mean LDL-cholesterol level of $161 \pm 26 \mathrm{mg} / \mathrm{dL}$, non-HDL cholesterol of $181 \pm$ $24 \mathrm{mg} / \mathrm{dL}$ and mean total cholesterol level of $239 \pm 23$ $\mathrm{mg} / \mathrm{dL}$. This means that 3 patients were strong positive with a mean LDL-C of $193 \pm 17 \mathrm{mg} / \mathrm{dL}$, non-HDL-C of $208 \pm 17 \mathrm{mg} / \mathrm{dL}$ and total cholesterol (TC) of $236 \pm 26$ $\mathrm{mg} / \mathrm{dL}$ and 6 patients borderline with a mean LDL-C of $146 \pm 10 \mathrm{mg} / \mathrm{dL}$, non-HDL-C of $168 \pm 13 \mathrm{mg} / \mathrm{dL}$ and TC of $227 \pm 8 \mathrm{mg} / \mathrm{dL}$. In 85 siblings the lipid screening test was performed and four individuals were positively screened with a mean LDL-C of $150 \pm 7 \mathrm{mg} / \mathrm{dL}$, nonHDL-C of $184 \pm 8 \mathrm{mg} / \mathrm{dL}$ and a mean TC of $231 \pm 10$ $\mathrm{mg} / \mathrm{dL}$ (Table 2). In all groups, no gender differences have been observed according to the screening lipid test.

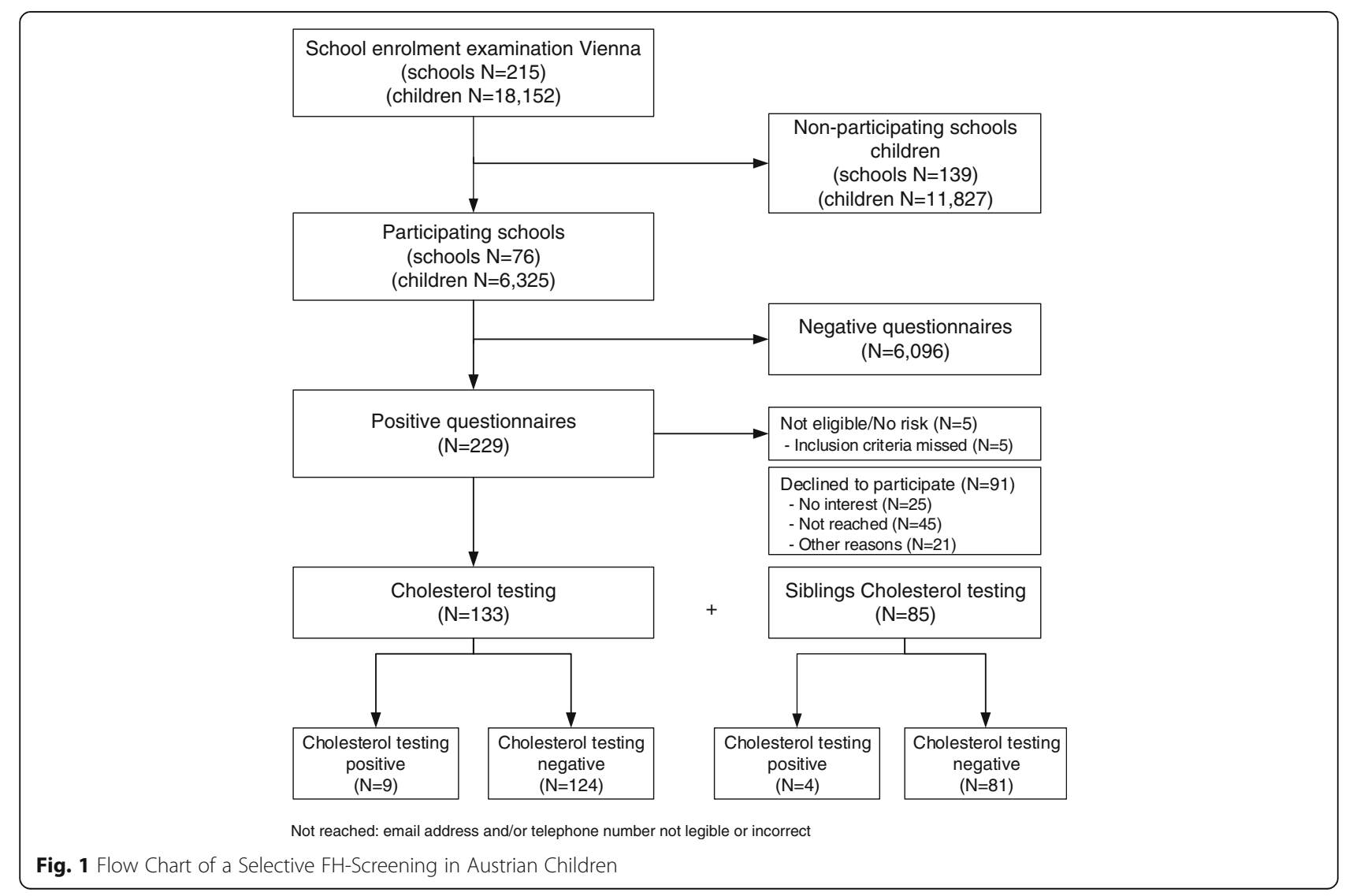


Table 1 Demographic characteristics

\begin{tabular}{|c|c|c|c|c|}
\hline & $\begin{array}{l}\text { Pre-school Children } \\
(N=133)\end{array}$ & $\begin{array}{l}\text { Index patients Positive } \\
(N=9)\end{array}$ & $\begin{array}{l}\text { Siblings } \\
\text { All } \\
(N=85)\end{array}$ & $\begin{array}{l}\text { Siblings } \\
\text { Positive } \\
(N=4)\end{array}$ \\
\hline & Median (Range) & Median (Range) & Median (Range) & Median (Range) \\
\hline Male & 73 (55\%) & $6(67 \%)$ & 31 (37\%) & $1(25 \%)$ \\
\hline Age (years) & $6(5-7)$ & $6(5-6)$ & $8(0.5-28)$ & $2(0.5-12)$ \\
\hline Body height $(\mathrm{cm})$ & $118(100-140)$ & $119(110-127)$ & $134(68-190)$ & 88.5 (68-160) \\
\hline Body weight (kg) & $22(14-49)$ & $22(20-27)$ & $31(7-88)$ & $11(7-42)$ \\
\hline BMI $\left(\mathrm{kg} / \mathrm{m}^{2}\right)$ & $15.8(10.7-30.7)$ & $16.0(15.3-16.7)$ & $16.5(8.9-34.7)$ & $14.5(13.5-16.4)$ \\
\hline
\end{tabular}

Data are presented as median and range, or as number of subjects (\%) $B M I$ Body Mass Index

After four months the cholesterol screening test from the capillary blood sampling was confirmed with venous blood sampling. No significant differences were found between the two methods. Table 2 summarizes the blood results from positive screened index patients. All positive screened index patients and positive screened siblings had a positive family history according to hypercholesterolemia in one parent and grandparent, but neither showed any other disease related with dyslipidemia nor presented xanthomas or xanthelasma, arcus lipoides, or atherosclerotic comorbidities. In four index patients and one positive screened sibling results for familial hypercholesterolemia showed a disease causing genetic mutation either on LDL-R or on ApoB.

\section{Sensitivity and specificity}

Based on familial hypercholesterolemia prevalence of 1 : 250 [5-7] and with the assumption that all children with positive questionnaires would have been included in the cholesterol testing $(n=229)$, the sensitivity and specificity of the selective FH-screening has been evaluated. For a positive cholesterol screening test the sensitivity is $60 \%$ and specificity is $97 \%$ (Table 3 ).

\section{Discussion}

In the current study, we have investigated the first screening for familial hypercholesterolemia in children from Austria. Various screening methods are recommended for different paediatric age groups. The American Academy of Pediatrics recommended a universal screening in children aged between 9 to 11 years, and rescreening at the age between 17 to 21 years [17]. Universal screenings were performed in five year old children in Slovenia [18] and in one to two year old children in the UK [19] at routine child immunisation visits. In Slovakia universal screening was conducted in children aged between 11 to 17 years during cholesterol screening visits [20]. In Austria routine medical checks in children are often not perceived by the parents and therefore, universal screening cannot reach the population. In consequence, we tried to establish a screening method for children at a time point, which assured to reach this young study population all over Vienna. In Vienna's public primary schools, annually repeated school enrolment examinations for pre-school children are performed by school physicians. Prior to the start of the study all school physicians were trained for this screening. We gave up universal screening because of limited time resources of the school physicians and legally problematic

Table 2 Cholesterol screening test

\begin{tabular}{|c|c|c|c|c|}
\hline & $\begin{array}{l}\text { Pre-school } \\
\text { Children } \\
(N=133)\end{array}$ & $\begin{array}{l}\text { Index patients } \\
\text { Positive } \\
(N=9)\end{array}$ & $\begin{array}{l}\text { Sibling } \\
\text { All } \\
(N=85)\end{array}$ & $\begin{array}{l}\text { Siblings } \\
\text { Positive } \\
(N=4)\end{array}$ \\
\hline & Median (Range) & $\begin{array}{l}\text { Median } \\
\text { (Range) }\end{array}$ & $\begin{array}{l}\text { Median } \\
\text { (Range) }\end{array}$ & $\begin{array}{l}\text { Median } \\
\text { (Range) }\end{array}$ \\
\hline $\mathrm{TC}(\mathrm{mg} / \mathrm{dL})$ & $155(99-281)$ & $233(218-281)$ & 152 (99-238) & $234(217-238)$ \\
\hline LDL-C (mg/dL) & $76(30-210)$ & $152(129-210)$ & $70(22-157)$ & $150(141-157)$ \\
\hline $\mathrm{HDL}-\mathrm{C}(\mathrm{mg} / \mathrm{dL})$ & $57(22-100)$ & $54(42-80)$ & $51(25-101)$ & $48(27-66)$ \\
\hline $\mathrm{TG}(\mathrm{mg} / \mathrm{dL})$ & $87(44-493)$ & $82(47-176)$ & $118(44-491)$ & $156(118-247)$ \\
\hline non-HDL-C (mg/dL) & $97(52-225)$ & $181(150-225)$ & $99(51-190)$ & 186 (172-190) \\
\hline $\mathrm{C} / \mathrm{HDL}$ ratio & $2.7(1.6-6)$ & $4(3-6)$ & $3(1.6-8)$ & $5(4-8)$ \\
\hline
\end{tabular}

Data are presented as median and range. Cholesterol screening test was performed by capillary blood sampling

TC Total Cholesterol, LDL-C Low Density Lipoprotein Cholesterol, HDL-C High Density Lipoprotein Cholesterol, TG Triglycerides, non-HDL-C non-HDL Cholesterol, C/ $H D L$ ratio Cholesterol/High Density Lipoprotein Ratio 
Table 3 Sensitivity and Specificity of a selective FH-Screening

\begin{tabular}{lllll}
\hline Prevalence & Sensitivity (\%) & Specificity (\%) & PPV (\%) & NPV (\%) \\
\hline $1: 250$ & 60 & 97 & 6.55 & 99.84 \\
\hline
\end{tabular}

Data are presented as percentage. PPV Positive Predictive Value, NPV Negative Predictive Value

presence of scientific staff at the school enrolment. The prevalence of heFH is estimated approximately one per 250 in the general population [5-7]. From 133 tested pre-school children, nine individuals were positivescreened. From 85 siblings, four individuals were identified to be positive. Therefore, the school enrolment examination might be an optimal time to reach all young aged children and to identify FH children in Austria. It would be an additional advantage that the knowledge of FH among all parents of pre-school children and the school physicians may improve, who are often primary care physicians, which helps to increase the FH awareness. Early identification of FH patients is essential and childhood is described as the optimal period for cholesterol screening [21]. During adolescence, the relatively reduced LDL-cholesterol may be problematic for a screening strategy $[22,23]$. Hence, a screening in childhood might be an appropriate and most effective screening to detect those patients. First line treatment consists of fat reduced diet and physical activity, but if necessary medication can be started from the age of $6-10$ years $[1,2]$.

In fact, the majority of patients suffering from $\mathrm{FH}$ are undiagnosed until their first often dramatic cardiovascular event [6]. How could that be changed?

The implementation of lipid screening in children has the strength to recognize $\mathrm{FH}$ and to prevent early atherosclerotic cardiovascular disease (ASCVD) [24], but also to identify other lipid disorders like obesity or combined dyslipidemia [25]. Patients suffering from familial hypercholesterolemia have a 100-times increased PCVD risk [26]. This was confirmed in the study by premature $\mathrm{CHDs}$ in first- and second-grade relatives. Early treatment is cost-effective in terms of cost per year of life saved [1] and should be implemented in high risk children to lower LDL-C. For the cholesterol screening test the Alere AfinionTM AS 100 Analyzer (Alere GmbH, Linz, Austria) has been used. For this kind of measurement only one drop of blood is needed, received from a finger stick. The benefits are that the measurement is fast and can be taken non-fasting by measuring directly TC, HDL-C, TG and additional calculation of LDL-C, non-HDL-C and C/HDL ratio. Moreover, for confirmation of the FH diagnosis in the patients' clinical criteria including family history, lipid status and genetic testing were used. Thereby, nine index patients could be detected in early childhood, which guarantees an excellent quality of life by strict lipid lowering therapy. In four index patients and also one positive screened sibling the diagnosis was genetically confirmed by either a pathologic LDL-R mutation or on ApoB mutation.

With the assumption that all children with positive questionnaires would have been included in the cholesterol testing based on the positive predictive value (9/ 133) of $6.77 \%$, a total number of 15 positive tested children could be detected, with a sensitivity of $60 \%$ and a specificity of $97 \%$. The sensitivity and specificity of the selective screening has been determined based on a prevalence of 1:250 [5-7]. However, the Austrian prevalence data of heFH is not available. Hence, previous published data on prevalence of 1:500 [27], would result into an increased sensitivity of this $\mathrm{FH}$ screening method. Therefore, this shows the potential which might be achieved with selective screening in early childhood. However, this is the first time of a screening method for FH in Austria and could show the high potential of finding affected children. Almost certainly universal screening during the school enrolment would increase the detection rate.

A limitation of the study was that we received questionnaires only from $35 \%$ of all Viennese children, who had their school enrolment examinations. Reasons not to be included into the screening were that school doctors had no sufficient time resources, little experience with studies, parents refused study participation and despite multilingual study documents language difficulties seemed to be the main factors, which may affect the outcomes of sensitivity and specificity for this heFH screening tool. From the positive questionnaires, almost $20 \%$ of parents could not be contacted as email address and/or telephone numbers were not legible or incorrect. Those aspects have to be improved for further screening periods as well as to increase the awareness of parents and school physicians for selective FH screening.

\section{Conclusions}

Early detection and prevention of cardiovascular diseases are essential for the commonly frequent genetic disease, familial hypercholesterolemia. Screening at early childhood by school physicians seems to be a successful strategy and possible. With this Austrian selective screening method, FH Kids Austria, we could find nine patients with strong positive or borderline LDL-cholesterol and/ or non-HDL cholesterol out of 133 blood tests. Prevention of cardiovascular diseases is essential and it is our duty to increase the awareness of this disease. Limitations of the FH Kids project were reduced participation of school physicians and refusal of the parents. Therefore, the school enrolment examination might be a suitable strategy to identify FH children in Austria. 


\section{Abbreviations}

ApoB: Apolipoprotein B; ASCVD: Atherosclerotic Cardiovascular Disease; C/ HDL-C ratio: Cholesterol/High-Density Lipoprotein Cholesterol ratio; CHD: Coronary Heart Disease; FH: Familial Hypercholesterolemia; HDLC: High-Density Lipoprotein Cholesterol; heFH: Heterozygous Familial Hypercholesterolemia; hoFH: Homozygous Familial Hypercholesterolemia; LDLAPR1: Low-Density Lipoprotein receptor Adaptor PRotein 1; LDL-C: Low Density Lipoprotein Cholesterol; LDL-R: LDL-Receptor; non-HDL-C: NonHigh-Density Lipoprotein Cholesterol; PCSK9: Proprotein Convertase Subtilisin/Kexin type 9; PCVD: Premature Cardiovascular Diseases; SPSS: Statistical Package for Social Science; TC: Total Cholesterol; TG: Triglycerides

\section{Acknowledgements}

We thank Katharina Truschner, Anselm Jorda, Jennifer Längle and Eva Pahr for assistance within the project, and all Viennese school physicians supporting this project.

\section{Authors' contributions}

AK, UH and SGP contributed to the study conception and design of the study. AK, NKW and PRE, contributed to the data acquisition. AK analysed and interpreted the data, and drafted the manuscript. SGP interpreted the data and made the critical revision. All authors have read and given final approval of the version to be submitted.

\section{Funding}

The study was funded by Sanofi-Aventis $\mathrm{GmbH}$, Amgen $\mathrm{GmbH}$, AOP Orphan Pharmaceuticals AG and Meda Pharma GmbH for translation costs of questionnaires and informed consent forms, printing costs and cholesterol screening test material.

\section{Availability of data and materials}

The datasets used and/or analyzed during the current study are available from the corresponding author on reasonable request.

\section{Ethics approval and consent to participate}

We received Institutional Review Board approval from the Medical University Vienna (MUV, EC Nr: 2019/2015). All parents were informed and provided their written informed consent.

\section{Consent for publication}

Not applicable.

\section{Competing interests}

The authors declare that they have no competing interests

\section{Author details}

${ }^{1}$ Division of Pediatric Pulmonology, Allergology and Endocrinology, Department of Pediatrics and Adolescent Medicine, Medical University of Vienna, Waehringer Guertel 18-20, 1090 Vienna, Austria. ${ }^{2}$ Municipal Authority of the City Vienna, Municipal Department 15, Health Service of the City of Vienna, Vienna, Austria.

\section{Received: 23 January 2018 Accepted: 17 June 2019}

\section{Published online: 25 June 2019}

\section{References}

1. Wiegman A, Gidding SS, Watts GF, Chapman MJ, Ginsberg HN, Cuchel M, et al. Familial hypercholesterolaemia in children and adolescents: gaining decades of life by optimizing detection and treatment. Eur Heart J. 2015;36: 2425-37.

2. Kusters DM, Hutten BA, McCrindle BW, Cassiman D, Francis GA, Gagne C, et al. Design and baseline data of a pediatric study with rosuvastatin in familial hypercholesterolemia. J Clin Lipidol. 2013;7:408-13.

3. Brown MS, Goldstein JL. A receptor-mediated pathway for cholesterol homeostasis. Science. 1986;232:34-47.

4. Ose L. Familial hypercholesterolemia from children to adults. Cardiovasc Drugs Ther. 2002;16:289-93.

5. Sjouke B, Kusters DM, Kindt I, Besseling J, Defesche JC, Sijbrands EJ, et al. Homozygous autosomal dominant hypercholesterolaemia in the
Netherlands: prevalence, genotype-phenotype relationship, and clinical outcome. Eur Heart J. 2015:36:560-5.

6. Nordestgaard BG, Chapman MJ, Humphries SE, Ginsberg HN, Masana L, Descamps OS, et al. Familial hypercholesterolaemia is underdiagnosed and undertreated in the general population: guidance for clinicians to prevent coronary heart disease: consensus statement of the European atherosclerosis society. Eur Heart J. 2013;34:3478-90.

7. Watts GF, Gidding S, Wierzbicki AS, Toth PP, Alonso R, Brown WV, et al. Integrated guidance on the care of familial hypercholesterolaemia from the international FH Foundation. Eur J Prev Cardiol. 2015;22:849-54.

8. Cuchel M, Bruckert E, Ginsberg HN, Raal FJ, Santos RD, Hegele RA, et al. Homozygous familial hypercholesterolaemia: new insights and guidance for clinicians to improve detection and clinical management. A position paper from the consensus panel on familial Hypercholesterolaemia of the European atherosclerosis society. Eur Heart J. 2014;35:2146-57.

9. Kavey RE, Daniels SR, Lauer RM, Atkins DL, Hayman LL, Taubert K. American Heart Association guidelines for primary prevention of atherosclerotic cardiovascular disease beginning in childhood. Circulation. 2003;107:1562-6.

10. Haney EM, Huffman LH, Bougatsos C, Freeman M, Steiner RD, Nelson HD. Screening and treatment for lipid disorders in children and adolescents: systematic evidence review for the US preventive services task Force. Pediatrics. 2007:120:189-214.

11. American Academy of Pediatrics. National Cholesterol Education Program: report of the expert panel on blood cholesterol levels in children and adolescents. Pediatrics. 1992:89(3 Pt 2):525-84.

12. Langslet $G$, Ose L. Screening methods in the diagnosis and assessment of children and adolescents with familial hypercholesterolemia. Expert Rev Cardiovasc Ther. 2013:11:1061-6.

13. Galema-Boers JM, Versmissen J, Roeters van Lennep HW, Dusault-Wijkstra JE Williams M, Roeters van Lennep JE. Cascade screening of familial hypercholesterolemia must go on. Atherosclerosis. 2015;242:415-7.

14. Plana N, Rodriguez-Borjabad C, Ibarretxe D, Masana L. Familial hypercholesterolemia in childhood and adolescents: a hidden reality. Clin Investig Arterioscler. 2017:29:129-40.

15. Ritchie SK, Murphy EC, Ice C, Cottrell LA, Minor V, Elliott E, et al. Universal versus targeted blood cholesterol screening among youth: the CARDIAC project. Pediatrics. 2010;126:260-5.

16. Eissa MA, Wen E, Mihalopoulos NL, Grunbaum JA, Labarthe DR. Evaluation of AAP guidelines for cholesterol screening in youth: project HeartBeat! Am J Prev Med. 2009;37(Suppl 1):71-7.

17. Expert Panel on. Integrated guidelines for cardiovascular $\mathrm{H}$, risk reduction in C, adolescents, National Heart L, blood I. expert panel on integrated guidelines for cardiovascular health and risk reduction in children and adolescents: summary report. Pediatrics. 2011;128(Suppl 5):213-56.

18. Wald DS, Bestwick JP, Morris JK, Whyte K, Jenkins L, Wald NJ. Child-parent familial hypercholesterolemia screening in primary care. N Engl J Med. 2016; 375:1628-37.

19. Klancar G, Groselj U, Kovac J, Bratanic N, Bratina N, Trebusak Podkrajsek K, et al. Universal screening for familial hypercholesterolemia in children. J Am Coll Cardiol. 2015;66:1250-7.

20. Fábryová L, Hlavatá A, Cižmárová E, Šimurka P, Debreová M, Dukát $A$, et al. Recommendations for diagnosis and treatment of dyslipidaemia in children and adolescents. Pediatr prax. 2011:12(Suppl 1):3-9.

21. Catapano AL, Graham I, De Backer G, Wiklund O, Chapman MJ, Drexel H, et al. 2016 ESC/EAS guidelines for the Management of Dyslipidaemias. Eur Heart J. 2016:37:2999-3058

22. Daniels SR, Gidding SS, de Ferranti SD. National Lipid Association Expert Panel on familial $\mathrm{H}$. pediatric aspects of familial hypercholesterolemias: recommendations from the National Lipid Association Expert Panel on familial hypercholesterolemia. J Clin Lipidol. 2011;5(Suppl 3):30-7.

23. Descamps OS, Tenoutasse S, Stephenne X, Gies I, Beauloye V, Lebrethon MC, et al. Management of familial hypercholesterolemia in children and young adults: consensus paper developed by a panel of lipidologists, cardiologists, paediatricians, nutritionists, gastroenterologists, general practitioners and a patient organization. Atherosclerosis. 2011;218:272-80.

24. Force USPST, Bibbins-Domingo K, Grossman DC, Curry SJ, Davidson KW, Epling JW, et al. Screening for lipid disorders in children and adolescents: US preventive services task Force recommendation statement. Jama. 2016; 316:625-33

25. Urbina EM de Ferranti SD. Lipid screening in children and adolescents. Jama. 2016;316:589-91. 
26. Kusters DM, de Beaufort C, Widhalm K, Guardamagna O, Bratina N, Ose L, et al. Paediatric screening for hypercholesterolaemia in Europe. Arch Dis Child. 2012;97:272-6.

27. Civeira F. Guidelines for the diagnosis and management of heterozygous familial hypercholesterolemia. Atherosclerosis. 2004;173:55-68.

\section{Publisher's Note}

Springer Nature remains neutral with regard to jurisdictional claims in published maps and institutional affiliations.

Ready to submit your research? Choose BMC and benefit from:

- fast, convenient online submission

- thorough peer review by experienced researchers in your field

- rapid publication on acceptance

- support for research data, including large and complex data types

- gold Open Access which fosters wider collaboration and increased citations

- maximum visibility for your research: over $100 \mathrm{M}$ website views per year

At BMC, research is always in progress.

Learn more biomedcentral.com/submissions 